\title{
CICLO DE ESTUDOS DE PROCESSO CIVIL
}

Comemoração da fundação dos Cursos Jurídicos no Brasil

Em comemoração à passagem de mais um aniversário da fundação dos Cursos Jurídicos no País, a Ordem dos Advogados do Brasil, Secional paranaense e à Associação dos Magistrados do Paraná, por seu Departamento Cultural, com a colaboração dos Diretórios Acadêmicos HUGO SIMAS (Faculdade de Direito da UFPr), Clotário Portugal (Faculdade de Direito de 
Curitiba) e Núcleo Estudantil da Faculdade de Direito da Universidade Católica, promoveram um CICLO DE ESTUDOS DE PROCESSO CIVIL, no período de 11 a 13 de agosto do corrente ano, no Salão Nobre da Faculdade de Direito da Universidade Federal do Paraná (Curitiba). O encontro despertou inusitado interesse nas classes jurídicas de todo o Estado, tendo dele participado, devidamente inscritos, entre professores, advogados, juizes de Direito, membros do Ministério Público e estudantes das três Faculdades existentes em Curitiba para mais de trezentos estudiosos da ciência processual.

Foram proferidas, durante os trabalhos culturais do certame, quatro conferências, a saber: no dia 11, pela manhã, Prof. J. J. Calmon de Passos, catedrático da.Faculdade de Direito da Universidade Federal da Bahia e presidente da secional da $O A B$ no mesmo Estado ("Processo Cautelar"); Prof. Athos Gusmão Carneiro, à tarde do dia 11, na qualidade de desembargador do Tribunal de Justiça do Rio Grande do Sul e do corpo docente da Faculdade de Direito da Universidade Federal de Porto Alegre. ("Intervenção de Terceiros - da Denunciação da lide"); dr. Sálvio de Figueiredo Teixeira, Juiz do Tribunal de Alçada de Minas Gerais e Professor da Faculdade dé Direito da UFMG, em Belo Horizonte ('Procedimento Sumaríssimo - Necessidade de sua reformulação - Questões controvertidas"'), às 10:00 horas do dia 12; e, finalmente, à tarde, Dr. Rogério Lauria Tucci, Professor da Faculdade de Direito da Universidade de São Paulo (Largo de São Francisco) e advogado militante nos auditórios paulistanos ("Julgamento conforme o estado do processo").

A sessão solene de abertura, com a presença de autoridades, e, efetivada no dia 11, pela manhã, foi presidida pelo Prof. Oto Luiz Sponholz, pres. da OAB-Pr.. A de encerramento, com a votação das conclusões sustentadas pelos conferencistas, realizada no dia 13, com início às 10:00 horas, foi desenvolvida sob a presidência do desembargador Lauro Lima Lopes, presidente da Associação dos Magistrados do Paraná. Todas as sessões culturais, de sua vez, foram presididas pelo professor e desembargador Ary Florencio Guimarães, catedrático de Direito Procesual Civil da Faculdade de Direito da UFPr e diretor-presidente do Departamento Cultural da Associação dos Magistrados do Paraná. Secretários: juizes Vicente Troiano Neto e Acaccio Cambi (da comarca de Curitiba) e Regina Helena Afonso, advogada nos auditórios paranaenses. Comissão de recepção: juiz José Ulisses Silveira Lopes (da comarca de Curitiba) e advogado Walter Borges Carneiro (pela OAB-Pr.). 


\title{
CONCLUSÕES
}

Apreciadas liminarmente pela Comissão de Súmulas do $\mathrm{Ci}$ clo, integrada pelos professores Egas Dirceu Moniz de Aragão, Ivan Ordine Righi (juiz do Tribunal de Alçada do Estado) e Joaquim Roberto Munhoz de Melo, da Faculdade de Direito da Universidade Federal do Paraná, são as seguintes as conclusões aprovadas pelo plenário, depois de discutidas amplamente nas sessões culturais e de debates:

\section{CONFERÊNCIA DO DIA 11 de agosto de 1983 (período da manhã) 9:00 horas. TEMA: PROCESSO CAUTELAR PROFESSOR: J. J. CALMON DE PASSOS}

\author{
CONCLUSÕES: \\ 1a.) - O livro III, do Código de Processo Civil, inclui e discipli- \\ na: \\ a) medidas essencialmente cautelares; \\ b) medidas provisionais; \\ c) medidas só procedimentalmente cautelares.
}

$2^{a}$.) - As medidas essencialmente cautelares têm como características fundamentais:

a) sua instrumentalidade: asseguram sempre o resultado útil de um processo de conhecimento ou de execução;

b) sua provisoriedade;

c) fundamentarem-se no fundado receio de que, antes de proferida a sentença no processo principal, venha a se tornar impossível ou improvável a atribuição do bem da vida que por meio dela se pretende obter (periculum in mora);

d) e na probabilidade de que a sentença, a ser proferida, se incline no sentido da existência do direito ao bem da vida que se pretende obter, em termos definitivos com ela (fumus boni juris).

3a.) - As medidas provisionais são decretådas tendo-se em vista o atendimento de atribuições deferidas ao magistrado, de prover sobre a boa marcha do processo e sobre as coisas e pessoas necessárias à formação de convencimento ou necessárias para sua constrição, ou para o atendimento do seu dever de prover sobre interesses de sujeitos, postos pelo ordenamento, sob tutela judicial.

4a.) - As medidas topologicamente cautelares se caracterizam porque nelas o Juiz provê sobre interesses materiais dos sujeitos, relacionados a interesses outros seus, principais, também de natu- 
reza substancial ou desprovidos dessa conexidade.

5a.) - 0 poder geral de cautela nada mais é que a pretensão à cautela, exercitada pela parte, mediante o procedimento ordinário cautelar porque presentes os fundamentos da pretensão cautelar e não previsto em lei nenhum procedimento especial na espécie.

Intervenções nos Debates:

Dr. Francisco Carlos Duarte (advogado).

Dr. Gil Trota Telles (Juiz do Direito).

Aprovadas, por unanimidade, na sessão de encerramento, realizada nesta data.

Em 13.8.83.

Acáccio Cambi

Secretário

CONFERENCIA DO DIA 11 de agosto de 1983

(período da tarde) - 15:00 horas.

TEMA: INTERVENÇĀO DE TERCEIROS

PROFESSOR: ATHOS GUSMĀO CARNEIRO

Inscrição para debates:

1) Prof. ROGÉRIO LAURIA TUCCI

2) Prof. SALVIO DE FIGUEIREDO TEIXEIRA

3) Prof. CALMON DE PASSOS

4) Dr. FRANCISCO DE PAULA XAVIER NETO

(Juiz de Direito)

5) Dr. GIL TROTTA TELLES (Juiz de Direito)

6) Prof. EDSON RIBAS MALACHINI (Juiz de Direito)

\section{CONCLUSŌES}

Tendo em vista sobretudo reforçar a instrumentalidade do processo e a eficiência prática da denunciação da lide, extraindo das normas legais vigentes o maior proveito possível em termos da eliminação definitiva dos litígios e de aplicação do direito material, proponho, sub censura, as seguintes conclusões:

19) - A não-denunciação da lide somente acarreta a perda da pretensão regressiva nos casos de garantia formal, ou seja, de evicção e de transmissão de direitos.

2ạ) - A posição do denunciado pelo réu é, na ação principal, a 
de litisconsorte do denunciante, nos exatos termos do artigo 75, I, do CPC; em conseqüência, o autor, procedente a demanda principal, poderá executá-la também contra o denunciado, embora com atenção aos limites em que foi procedente a ação regressiva e à natureza da relação de direito material.

3a) - A ação autônoma regressiva subsiste quer nos casos em que é "relativa" a obrigatoriedade de denunciação da lide (casos de responsabilidade civil), como ainda em hipóteses outras, inclusive nos casos em que a citação do denunciado não se efetivou nos prazos legais (art. 72, § 2?, do $\mathrm{CPC}$ ) sem que para tanto tenha concorrido culpa do denunciante.

4ạ) - As denunciações "sucessivas", previstas no artigo 73 do CPC, poderão ser também feitas "coletivamente", ou seja, requeridas "em conjunto" pelo denunciante, assim abreviando o processo e melhor se assegurando do êxito da demanda indenizatória de regresso, no caso de insolvência ou ausência de algum dos anteriores proprietários na cadeia dominial.

Aprovada, por unanimidade, na sessão de encerramento, realizada nesta data.

Em 13.8.83.

Acáccio Cambi

Secretário

CONFERÉNCIA DO DIA 12 de agosto de 1983

(período da manhã) 9:00 horas

\section{TEMA: PROCEDIMENTO SUMARISSIMO \\ PROFESSOR: SALVIO DE FIGUEIREDO TEIXEIRA}

Inscrição para debates:

1) Prof. J. J. CALMON DE PASSOS

2) Dr. FRANCISCO CARLOS DUARTE (Advogado)

3) Dr. ALIR RATACHESKI (Advogado)

4) Dr. ANTONIO MORIS CURY (Advogado)

5) Dr. ALDO PARZIANELLO (Advogado)

6) Dr. ALTAMIRO J. SANTOS (Advogado)

7) Dr. JOSÉ MAURICIO PINTO DE ALMEIDA

(Prof. Faculdade de Direito Curitiba)

8) Prof. EDSON RIBAS MALACHINI (Juiz de Direito)

9) MANOEL CAETANO F. FILHO

(Prof. Fac. Federal) 
10) Dr. FRANCISCO DE PAULA XAVIER NETO

(Juiz de Direito)

11) Dr. PAULO CESAR BACHAMANN ALVES

(Assessor Tribunal de Alçada)

CONCLUSŌES

1a) - 0 jurista deve participar ativamente da formulação e do aperfeiçoamento da ordem jurídica.

2a) - A atual má qualidade da tutela jurisdicional, vinculada à crise institucional do país e à ausência de autonomia do Poder Judiciário, reclama nova estrutura da organização judiciária e alteração na legislação processual.

3a) - No aprimoramento das normas processuais deve ter prioridade o aperfeiçoamento do atual procedimento sumaríssimo.

Aprovada, por unanimidade, na sessão de encerramento realizada nesta data.

$$
\begin{gathered}
\text { Em 13.08.83 - Accácio Cambi } \\
\text { Secretário }
\end{gathered}
$$

Art. 10. O capítulo III do ... .

\section{ESBOÇO A TITTULO DE SUGESTĀO}

Capítulo III

Dos procedimentos sumário e sumaríssimo.

Art. 275. Observar-se-á o procedimento sumário:

I - nas causas cujo valor não exceder vinte (20) vezes o maior salário mínimo vigente à época do ajuizamento da demanda;

II - nas causas, qualquer que seja o valor:

a) que versem sobre a posse ou direitos reais relativos a móveis e semoventes;

b) de arrendamento rural e de parceria agrícola;

c) que tenham por fundamento prescrições de convenção de condomínio, ressalvados os casos sujeitos a via executiva;

d) de indenização por danos decorrentes de acidente de ve ículo de via terrestre;

e) de cobrança de seguro obrigatório;

f) de cobrança de honorários dos profissionais liberais, ressalvado o disposto em legislação especial.

Parágrafo único. Esse procedimento não será observado nas ações relativas ao estado e a capacidade das pessoas.

Art. 276. Na petição inicial (arts. 282 e 283) o autor apresentará o rol de testemunhas e, se requerer, formulará os quesitos e poderá apresentar assistente técnico.

§ 10. - O juiz determinará a citação do réu para responder no 
prazo de dez (10) dias, designando, no mesmo despacho, data para a audiência de instrução e julgamento.

§ 20. - Com a contestação, o réu apresentará seu rol de testemunhas e, em caso de perícia, formulará quesitos e poderá indicar assistente técnico.

§ 30. - A impugnação ao valor da causa (art. 261), bem como as exceções (art. 304), serão argu ídas na contestação.

Art. 277. Ocorrendo qualquer das hipóteses dos arts. 329 e 330, será proferida sentença em julgamento conforme o estado do processo.

Art. 278. Não sendo caso de julgamento antecipado, a sentença será proferida em audiência, logo que encerrados os debates orais, ou no prazo de dez (10) dias.

§ 10. - Antes de iniciada a instrução o juiz tentará conciliar as partes. (art. 448).

§ 20. - Deverá o juízo, sempre que possível, designar data apenas para fins de conciliação, se as partes tiverem domicílio ou residência na mesma comarca ou em comarcas próximas. A convocação, para esse fim será por via postal, em mãos próprias, com a advertência de que, não comparecendo o autor, o processo será arquivado, não comparecendo o réu, os fatos apontados na inicial serão tidos como verdadeiros.

Art. 279. No procedimento sumário não cabe ação declaratória incidental, oposição e chamamento ao processo. $\mathrm{O}$ agravo somente poderá ser interposto em sua forma retida e a sentença deverá ser proferida dentro do prazo de cento e vinte (120) dias, a contar da propositura da ação.

Art. 280. 0 procedimento sumaríssimo poderá ser adotado nas ações de cobrança ou de indenização, cujo valor não exceder dez (10) vezes o maior salário mínimo vigente à época do ajuizamento da demanda.

$\S 10$. - Somente é admissível o procedimento sumaríssimo entre partes residentes em lugar certo, capazes de transigir, e quando formulado pedido l íquido.

§ 20. - As partes comparecerão a juízo acompanhadas das testemunhas e apresentando os documentos relativos à lide. Após ouvidos os litigantes, promoverá o juiz a tentativa de conciliatória. Não obtida a conciliação, o juiz inquirirá as testemunhas sobre os pontos essenciais da lide, apreciará os documentos e proferirá de imediato a sentença. Os depoimentos serão colhidos sem maior formalidade.

§ 30. - Comparecendo a juízo apenas o autor, a petição será apresentada por escrito, em duas (2) vias, ou formulada verbal- 
mente, devendo o serventuário, nessa segunda hipótese, tomála por termo. Na mesma oportunidade, será designada data para a audiência, com imediata intimação do demandante e expedição de carta citatória do demandado (art. 223), registrada e para entrega em mãos próprias. A citação por mandado será utilizada apenas em caráter supletivo.

§ 40. - Não comparecendo o autor à audiência, será extinto o processo sem julgamento do mérito. Não comparecendo o réu, os fatos apontados pelo autor na inicial serão tidos como verdadeiros (art. 319).

§50. - O termo da audiência consignará a identificação das partes, anotará os pontos fundamentais do pedido e da resposta, resumirá as informações prestadas pelas testemunhas e conterá, por extenso, a sentença.

§ 60. - As decisões interlocutórias somente poderão ser impugnadas por agravo retido.

$\S 70$. - 0 juiz poderá julgar inadequado o procedimento sumaríssimo, como nos casos em que considere imprescindível a prova pericial processada em juízo ou a expedição de precatória. Desse julgamento não cabe recurso.

$\S 8^{\circ}$. - Nas causas sob procedimento sumaríssimo, a sentença deve ser proferida no prazo de trinta $(30)$ dias, isentas tais causas de quaisquer despesas.

§ 90. - As leis de organização judiciária poderão estabelecer órgãos especiais para o julgamento dos recursos interpostos nas causas sob este procedimento.

$\S 10$ - Não cabe, neste procedimento, a declaratória incidental, a reconvenção, a oposição e a intervenção de terceiros.

Art. 281. Nas causas sob procedimento sumário ou sumaríssimo, podem as partes, por opção manifestada na inicial e na contestação, ou por ambas formulada no in ício da audiência, autorizar o juiz julgar por equidade, fora das regras e formas de direito, caso em que a sentença não fica sujeita a recurso, salvo se o contrário convencionarem as partes.

Parágrafo único - $\mathrm{O}$ julgamento por equidade não dispensa o juiz de fundamentar sua decisão.

Art. 20. Fica revogado o $\S 20$. do art. 315 , passando o atual $\S 10$ a ser parágrafo único.

Art. 30. Ao art. 530 é acrescentado o seguinte parágrafo: “Parágrafo único. Não são admissíveis embargos infringentes nas ações sob procedimento sumaríssimo".

Art. 40. A expressão "procedimento sumar íssimo" fica substitu í- 
8. A cobrança de honorários advocatícios somente pode verificar-se pela via executiva desde que no contrato escrito (Lei no. 4.215/63, art. 100, parágrafo único) haja valor estabelecido (CPC, art. 586), uma vez que a ação executiva mencionada na citada lei é a do CPC anterior

9. Os recursos interpostos contra as sentenças proferidas nos processos de que trata o art. 107 do "Estatuto da Terra" têm efeito também suspensivo.

10. O qualificativo "municipais", da terra "g", do inciso II, do art. 275, CPC, somente se refere a posturas.

11. A Lei no. 6.205/75 (s/"valor de referência") se aplica ao procedimento sumaríssimo.

12. A via executiva não é hábil para a cobrança, pelo síndico, de quota de participação dos condôminos nos encargos (tributos e despesas) do condom ínio.

13. Em se tratando de imóvel urbano loteado, o promitente comprador, munido do contrato formalizado, não precisará da ação de adjudicação compulsória mencionada no art. 10. da Lei no. 6.014. 0 mesmo, entretanto, não se dá em relação ao imóvel não-loteado, haja vistá que, no tocante a este, se aplica o citado dispositivo legal, vigente ainda o art. 22 do DL ñ. 58/37.

\section{Intervenção do advogado}

“Prof. Sálvio:

1) - Vossa Excelência empresta especial ênfase ao descompasso entre o objetivo com que foi criado o procedimento sumaríssimo e a sua aplicação no foro, concluindo:

"O que tem merecido irônicas designações de "Q mais ordinário de todos e o ordinar íssimo."

2) - Entendemos que, no procedimento sumaríssimo, está a solução para grande parte da crise que envolve a Justiça Brasileira que, hoje, está impossibilitada dar prestação jurisdicional adequada tanto aos pobres como aos ricos.

3) - Instituto generoso, criado para atender os mais necessitados, não se lhe deu, entretanto, os instrumentos necessários para sua efetiva realização.

4) - 0 primeiro e enorme erro reside no fato de serem distribuidas as ações respectivas para os mesmos juízes que processam e julgam as de procedimento ordinário.

5) - Ora, as deste vêm se somar às daquele procedimento, tornando impossivel, senão desumano, exigir - de que os processos, em primeiro grau de jurisdição, sejam julgados dentro de no- 
venta dias.

6) - O procedimento sumar íssimo pressupõe a existência de Juizo próprio e privativo bem como a insenção de pagamento de custas e despesas processuais, em primeira instância.

7) - A primeira exigência para que ele se torne instituto realmente eficaz e vivo será a criação do Juizado Especial do Procedimento Sumaríssimo, restrito aos grandes centros urbanos, constituido de juizes de carreira, mas especializados.

8) - Aos Tribunais de Justiça de cada Estado caberá, obedecidos os critérios de exigência de cada comarca, criá-lo, por meio da Lei de Organização e Divisão Judiciárias, e prover os cargos de Juiz de Direito, o de escrivão e de seus auxiliares, bem como o de oficial de justiça, estes todos remunerados pelo Estado.

9) - A segunda exigência diz respeito às despesas de processo e taxa judiciária.

Em primeiro grau de jurisdição não devem incidir despesas processuais, nem taxa judiciária. Por isso, os serventuários deverão ser remunerados pelo Estado.

As despesas processuais e taxa judiciária só seriam devidas, na hipótese de apelação, pelo apelante.

Estas as considerações, que submeto ao exame de Vossa Excelência, professor Sálvio de Figueiredo Teixeira, ao mesmo tempo em que, se acolhidas, indagaria da possibilidade de serem incluidas, no capítulo das suas proposições, mais as seguintes:

14) Os Tribunais de Justiça, através da Lei de Organização e Divisão Judiciárias, criarão o Juizado Especial do Procedimento Sumaríssimo e proverão os cargos de Juiz de Direito, escrivão, seus auxiliares e de oficial de justiça, estes remunerados, também, pelo Estado.

15) As despesas processuais e a taxa judiciária serão recolhidas ao Tesouro do Estado, pelo vencido que apelar, mediante guia própria, a título de renda eventual ou a que lhe atribuir a lei."

CONFERÉNCIÁ DO DIA 12 de agosto de 1983 (período da tarde) - 15:00 horas.

\section{TEMA: JULGAMENTO CONFORME O ESTADO DO} PROCESSO

PROFESSOR: ROGÉRIO LAURIA TUCCI

\section{CONCLUSŌES *}

Ante todo o expendido, parece-nos correto estabelecer as 
seguintes conclusões, referentemente aos temas versados neste breve estudo:

Primeira) 0 julgamento conforme o estado do processo divide-se, apenas, em julgamento segundo o estado dos autos e julgamento antecipado da lide, ambos mediante sentença que põe termo ao processo, respectivamente, sem e com exame do meritum causae.

Não compreende, portanto, o ato decisório de saneamento do processo, de natureza interlocutória, pela qual "o juiz, verificando ser admissível a ação e regular o processo, o impele em direção à audiência, por não estar madura a causa para o julgamento do mérito" (cf. JOSÉ CARLOS BARBOSA MOREIRA, O novo processo civil brasileiro cit., pág. 153).

Segunda) $O$ indeferimento liminar da petição inicial dá-se, em regra, através de sentença em que o juiz ou tribunal extingue o processo sem julgamento do mérito.

Essa modalidade de julgamento segundo o estado dos autos explica-se por ter o processo iniciada sua formação com o ajuizamento da ação, "tanto que a petição inicial seja despachada pelo juiz, ou simplesmente distribuída, onde houver mais de uma vara" (cf. artigo 263, primeira parte, do Código de Processo Civil), assim também, no primeiro caso, quando "protocolada, se o magistrado estiver ausente" (cf. THEOTÔNIO NEGRĀO, op. cit., pág. 111, nota 2 ao apontado artigo 263).

Terceira) A indicação do artigo 329, segunda parte, do Código de Processo Civil revela a previsão de julgamento antecipado da lide, não só nas circunstâncias alvitradas no artigo 330, como, por igual, em se tratando de reconhecimento da procedência do pedido, pelo réu, de transação, de pronunciação da decadência ou da prescrição ou de renúncia, pelo autor, ao direito sobre que se funda a ação - casos em que ocorre a extinção do processo com julgamento do mérito (cf. artigo 269, incisos II a V).

Conseqüentemente, a sentença homologatória de reconhecimento do pedido, de transação ou de renúncia à pretensão, da mesma maneira que o ato decisório de reconhecimento da decadência ou da prescrição, diz respeito ao mérito da causa, consistindo, portanto, num ato compositivo da lide submetida à apreciação judicial.

Quarta) Indeferida liminarmente a petição inicial, e havendo apelação do autor, o tribunal não pode impor-Ihe, ex-officio, a condenação no pagamento dos honorários de advogado constituído pelo réu, citado para acompanhar o recurso, nos termos do 
diposto no artigo 296 do Código de Processo Civil. (Aprovada, por maioria, em votação por destaque).

Impedem-no, a par da proibição da "reformatio in peius", no vigorante sistema processual civil brasileiro, as preceituações contidas nos $\S \S 10$. e 20 . do artigo 20 do mesmo Diploma legal, de sorte a tornar necessária, em prol da obtenção da verba honorária decorrente da confirmação da sentença indeferitória da petição inicial, a interposição de recurso adesivo, pelo réu.

Quinta) A revelia em sentido estrito, ou seja, a decorrente da falta de resposta do réu (devida e realmente citado) ao pedido formulado pelo autor, no prazo legal, produz dois efeitos - um material, previsto no artigo 319 do Código de Processo Civil, segundo o qual, em regra, se reputam verdadeiros os fatos alegados pelo demandante, e não contestados pelo demandado; e outro processual, prescrito no artigo 330 , inciso $\mathrm{II}$, determinante do julgamento antecipado da lide.

Este, todavia, pode ser tanto favorável, como desfavorável, ao autor beneficiado pela omissão do réu, pois, embora adstrito aos fatos afirmados pelas partes, "é da atribuição do juiz conhecer da matéria de direito, sem que nessa parte se encontre vinculado e embaraçado pela atitude dos litigantes". (cf. JOSÉ ALBERTO DOS REIS, Breve estudo sobre a reforma do processo civil e comercial, $2^{a}$. ed., Coimbra, 1929, pág. 119).

Reafirma-se, aí, induvidosamente, o vigor de aforismas que se tradicionalizaram no âmbito do Direito Processual, a saber: "Narra mihi factum dabo tibi ius" e "Iura novit curia".

Sexta) Inaplicável afigura-se o disposto no artigo 319 do Código de Processo Civil, referentemente à revelia em sentido estrito do autor-reconvindo, na reconvenção.

Ocorre, então, segundo preciso ensinamento de JOSÉ FREDERICO MARQUES, op, et vol. cit., págs. 94/95, apenas o descumprimento do ônus da impugnação especificada dos fatos, com as conseqüências estabelecidas no artigo 302.

$E$, de resto, não há como cogitar-se, em tal caso, da incidência do efeito processual da revelia, até porque, por força da regra estabelecida no artigo 318, ação e reconvenção devem ser julgadas, antecipadamente ou não, numa só sentença.

Em 13.8.83.

Acáccio Cambi

Secretário.

\footnotetext{
Aprovadas, por unanimidade, com exceção da quarta conclusão - aprovada por maioria -, na sessão de encerramento, realizada nesta data.
} 